Article

\title{
Micro-Operating Mechanism Approach for Regulatory Sandbox Policy Focused on Fintech
}

\author{
HaeOk Choi and KwangHo Lee ** \\ Science and Technology Policy Institute, 508 Building B, Sejong National Research Complex 370, \\ Sicheng-daero, Sejong 30147, Korea; hochoi@stepi.re.kr \\ * Correspondence: leekh@stepi.re.kr
}

Received: 15 September 2020; Accepted: 30 September 2020; Published: 1 October 2020

\begin{abstract}
To determine the micro-operating mechanism(MoM) of enterprises participating in the regulatory sandbox policy in fintech, this study analyzes the structure of enterprise innovation competencies and derives relevant implications. The results reveal that large, middle-standing, and small and medium-sized enterprises focus on security, infrastructure, and user-related technology development, respectively, to enhance their innovation competencies. The security-related issues considered by large enterprises entail relatively high costs in initial technology development and are closely related to infrastructure building. Large enterprises are focused on developing overall security-related technologies, whereas middle-standing enterprises are striving to develop infrastructure-related technologies, with particular emphasis on elementary technologies. Small and medium-sized enterprises are also making efforts to develop user-centered technologies that can directly be used in fintech. As a method to implement regulatory sandboxes tailored to the needs of participating enterprises in South Korea, this study will help to determine the MoM of such participants and establish strategies to support them sustainably in terms of evidence-based policy.
\end{abstract}

Keywords: MoM(micro-operating mechanism); regulatory sandbox; fintech; type by enterprise; innovation competencies; patents data; evidence-based policy

\section{Introduction}

Many countries around the world are implementing regulatory reform through regulatory sandboxes, which were first attempted in the fintech field as a way to create new technologies and services that have been blocked by regulations [1-3]. However, due to the side effects of being transplanted overseas, we have begun to recognize the need for an institutional transplant process tailored to different financial environments and characteristics at individual companies by countries. Until now, research on the regulatory sandbox itself has been limited because it has been dominated by government-oriented studies $[4,5]$. This study focuses on the innovation capabilities of Korean companies participating in the regulatory sandbox within the fintech sector and aims to help establish a tailored policy based on a company's characteristics. To evaluate these ideas, this research utilized semantic analysis focusing on the contents and titles of patents, which are unstructured data, to overcome the limitations of earlier studies [6,7]. The former research mainly focused on the frequency and regional distribution of patents, so there was a limitation to utilize (unstructured data) the contents of patent creation. So, this research tries to utilize the characteristics of each company occurring in actual innovation creation activities. The micro-operation mechanism implies that it is necessary to design policies suitable for each characteristic by analyzing micro-structural characteristics appearing in the process of actual system implementation.

The regulatory sandbox policy in fintech began with concerns about the weakening of global competitiveness due to limitations imposed by the government's regulatory policy on the ability 
to rapidly develop technology [8]. In particular, data collection and utilization have important value through the transition to the data economy; as data-based services are launched, the fintech industry is being activated [9]. As new technologies and services are developed, efforts are being made to overcome difficulties caused by institutional voids in government policies [10]. In particular, the fintech field has high initial infrastructure costs which means that they should often be conducted as a government-led business. In this process, government-led system design should preemptively respond to regulations by selecting the impeding factors of new industries and services due to likely issues, such as overregulation, system vacancy, and system duplication. The regulatory sandbox promotes policies that value speed as a means of regulatory reform.

This study is significant since it helps to analyze the innovation competencies of the enterprises participating [11-13] in the regulatory sandbox policy. It is implemented as part of regulatory innovation and uses these competencies as a reference that establish related tailored policies in the future in terms of evidence-based policy.

\section{Literature Review}

The micro-operation mechanisms' theoretical evolution comes from the rational selection system, policy network model, and policy advocacy coalition model. These items explain the system and describe the mechanism of the policy process centered on the constituent variables within each theory. Nevertheless, there was a limitation in being unable to explain the specific mechanism of the policy process by linking macro and micro variables. Therefore, in order to overcome the limitations of existing studies, this study utilized ACI as a basic theoretical framework for research on micro-operation mechanisms.

Examining regulatory sandboxes using MoM (micro-operating mechanism), actor-centered institutionalism (ACI), which can analyze regulatory policy with a focus on interactions among actors within the system, was considered suitable for this study. Furthermore, the study utilized a scientific analytical technique to analyze innovation competencies [14-16], as well as unstructured data that were the contents or titles of patent data for each type of enterprise; accordingly, enterprises were categorized into different types to clarify their structures and characteristics.

$\mathrm{ACI}$ is suitable for examining the complex mechanisms of policies as a single theory, rather than an integration of multiple theories. Proposed by Scharpf [17,18], ACI postulates that policies are produced because of interactions among actors in institutional settings. It is similar to the rational choice model in that it focuses on actors' preferences and strategic choices. It also takes the same stance as historical institutionalism in that it acknowledges institutional influence over actors. However, institutional influence over actors merely restricts the scope of actors' appropriate actions; the specific action to be taken within that scope is determined by the actors' preferences and strategic choices. In other words, active actors are postulated, which distinguishes ACI from historical institutionalism, which focuses on the passive role of actors. Moreover, since it enables the formation of actors' preferences and strategic choices in the institutional context, $\mathrm{ACI}$ is different from the rational choice model, which limits the actors' preference for specific economic interests. In other words, ACI is a model that combines the rational choice model, which emphasizes the strategic choice of actors, and historical institutionalism, which stresses institution.

To date, research on ACI has focused on how the actors influenced by an institution behave, rather than how the institution influences the actors. Institutional settings that affect actors' choices are the remote causes of policy outcomes, whereas the results of actors' interactions are the proximate causes of policy outcomes [18] (p. 3). Therefore, ACI assumes policies to be linked to constellations and modes of interactions comprising institutional settings, actors with capabilities and orientations, combinations of strategies, and appropriate payoff [17].

First, the institutional setting is a factor that restricts the behaviors of participating actors since it serves as a venue for interactions among the actors and determines the overall framework of the game. However, since these constraints are not decisive, the final policy outcome is determined by the interactions among actors. Second, actors are composite constructs characterized by capabilities 
and orientations (preferences and perceptions) [18] (pp. 43-44). Capabilities are behavioral resources that enable or limit competencies, as well as the right to participate, refrain from participating, or make autonomous decisions in the policy process. In other words, they refer to not only financial and human resources but also the actors' competencies and roles defined by the law and sustained relationships. Orientations indicate perceptions of and preferences for the maintenance of status quo, causes of problems, efficacy in the behavioral process, and the process' outcomes [18] (pp. 62-63). Perception is a subjective cognitive orientation regarding phenomena, including facts and causal relations, and the criteria for judgment are established under a theory or an institutional structure that make autonomous decisions in the policy process. Furthermore, preference is a concept that is classified into interests, norms, identities, and interaction orientations [18] (p. 64). Third, constellations refer to the static picture that appears in interactions and combines actors' characteristics (perceptions, preferences, and capabilities) with a combination of strategies, represented by the game matrix [18] (pp. 44-72). Constellations comprise players who participate in the specific game, their strategy options, outcomes of a combination of strategies, and the preferences of these outcomes. These game constellations do not individually affect interactions but affect them in a configurational manner; hence, various elements must all be considered in the analysis. Game constellations in interactions appear at the level of potential conflicts in actual policy interactions. Moreover, they are related to the type of game, as that determines different aspects of how the conflicts will be resolved and how the players will maximize their interests by adjusting their strategies or making decisions with others. Therefore, constellations are the appropriate measure to determine the choices of players among actual policy options [17] (p. 72).

Finally, the variable of interactions is a dynamic aspect within which conflicts are developed; the types of interactions include unilateral action, negotiated agreement, majority vote, and hierarchical direction. These are standardized interaction types that appear in combination in real life and are influenced by the institutional structure [17] (p. 47). This aspect of interactions is a key variable that affects the determination of the direction of final policy outcomes along with the institutional setting.

Therefore, this study used ACI as a theoretical framework to determine the MoM of enterprises. The use of ACI helped to structuralize various entangled factors and determine their characteristics. This study's analysis of enterprise structural characteristics has implications for the establishment of tailored policies through regulatory sandboxes in fintech.

To date, studies on regulatory sandboxes have mostly focused on the introduction of regulatory institutions in certain countries [3,5-13] or on the current state of such institutions implemented in certain fields $[1,14,15]$. However, these studies have been limited by their inability to adequately determine the MoM innovation capacities. Therefore, this study is significant in that it analyzes innovation competencies as the MoM of enterprises participating in the regulatory sandbox policy in fintech and discusses its implications.

\section{Methodology}

By using patent contents, this study examined the MoM of enterprises participating in the regulatory sandbox policy in fintech. The structural characteristics and innovation competencies of participating enterprises were analyzed by using MoM of regulatory sandboxes and the presented methods to apply them back to tailored policies $[19,20]$.

To do so, the study first adopted the regulatory sandbox policy as part of the regulatory innovation at the governmental level to create new industries and services that could overcome the difficulties caused by existing regulations. Accordingly, prior to analysis, this study conducted a literature review on the regulatory sandbox policy and examined various related trends.

Second, this study interviewed relevant experts (around 20 peoples between 1 April and 30 June 2020) to understand the innovation competencies of regulatory sandbox polices. 
Third, this study searched for credit information data using a list of participants limited to participants in the fintech sector of the regulatory sandbox and classified them by type of enterprise into large, middle-standing, and small and medium-sized enterprises.

To search for patent data, the names of the participating enterprises were converted into applicant codes by utilizing the Korea Intellectual Property Rights Information Service of the Korean Intellectual Property Office. Using these applicant codes and categories, patent data spanning 10 years (from 1 July 2011 to 1 July 2020) were collected. Among the types of patent-related attribute data that were collected, unstructured data pertaining to titles and contents were used to examine the MoM of enterprises.

Further, a group network analysis using NetMiner, a network analytical tool, was performed on the collected data. The results were used to process the data and confirm the ratio by organization and group, then derive conclusions (see Figure 1).

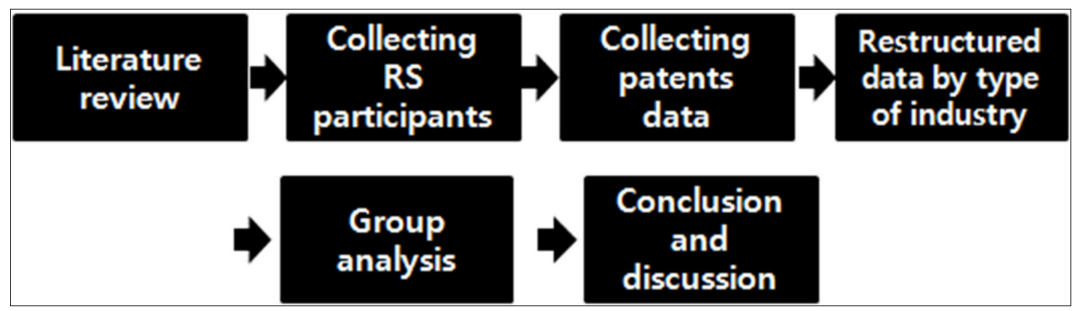

Figure 1. Research process.

\section{Results}

This study aimed to analyze the innovation competencies of enterprises participating in regulatory sandboxes in fintech. To clarify innovation competencies from a microscopic perspective, an analysis was conducted by classifying enterprises by type into large, middle-standing, and small and medium-sized enterprises based on patent data (see Figure 2).

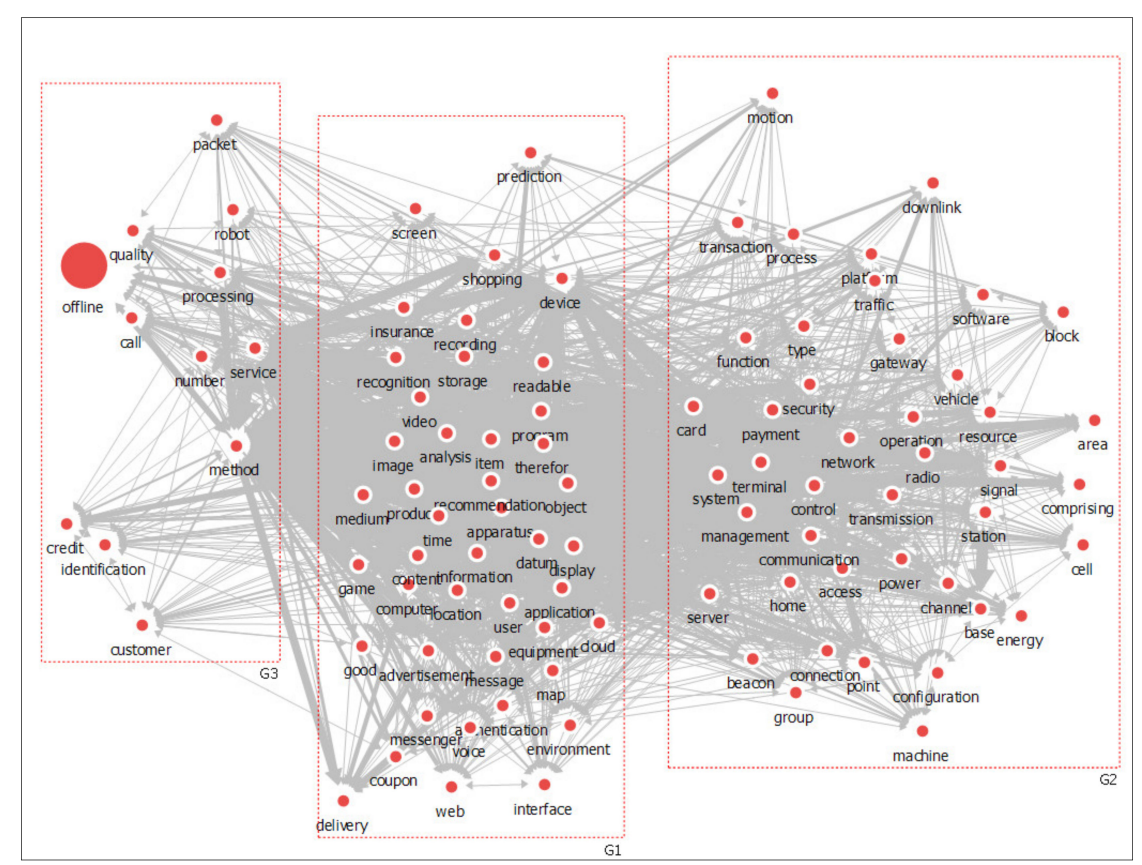

Figure 2. Results of group network analysis. Note: Nodes represent keywords, links show the relationship among nodes that appear as a result of analysis. The size of the nodes is related to their weight (the larger the node, the higher the frequency). Through semantic network analysis, the connection between nodes was visualized with the relationship frequencies. 
The following shows the main keywords, frequency, and centrality of each group from the cluster group analysis result. As a result of patent analysis, companies in the fintech field that participate in the regulatory sandbox can be divided into three groups. These can be labeled as infrastructure-related issues (G1), complementary issues (G2), and G3 (user-related issues).

First, infrastructure-related issues (indicated as G1) represented major issues related to the infrastructure of fintech; relevant keywords were apparatus, device, information, and computer. These issues revealed that the infrastructure-related innovation competencies that can support security in enterprise are enhanced by the application of new technology in fintech. It is important to build infrastructure that can safely manage and distribute users' funds. Furthermore, it was indicated that the industry developed because of the advancement of infrastructure-related technology to supplement funds.

Second, security-related issues (G2) included keywords such as system, server, network, control, payment, and security. The establishment of security technology in fintech enterprises helps to protect users when a financial company needs to prove that users permitted its transactions. Currently, the issues in developing technology for security are concentrated in systems, servers, and networks. This shows that security-related issues are closely related to the overall system operations of fintech, which are closely related to G1 (infrastructure-related issues). In particular, security-related issues involve the overall system, unlike infrastructure-related issues, whereas infrastructure represents detailed physical technical factors.

Third, user-related issues (G3) showed high frequencies for keywords such as method, service, call, processing, and credit. This indicates that technology related to stability in fintech transactions has been developed through credit guarantee in transactions. This shows that technology has been developed in terms of methods and services for credit guarantee, since there is an urgent need to establish safeguards for users with the development of fintech (see Table 1). 
Table 1. Results of group network analysis.

\begin{tabular}{|c|c|c|c|c|c|c|c|c|c|c|c|}
\hline \multicolumn{4}{|c|}{ G1 (Infrastructure-Related Issues) } & \multicolumn{4}{|c|}{ G2 (Security-Related Issues) } & \multicolumn{4}{|c|}{ G3 (User-Related Issues) } \\
\hline Keywords & Frequency & $\begin{array}{c}\text { Degree } \\
\text { Centrality }\end{array}$ & $\begin{array}{c}\text { Node } \\
\text { Betweenness } \\
\text { Centrality }\end{array}$ & Keywords & Frequency & $\begin{array}{c}\text { Degree } \\
\text { Centrality }\end{array}$ & $\begin{array}{c}\text { Node } \\
\text { Betweenness } \\
\text { Centrality }\end{array}$ & Keywords & Frequency & $\begin{array}{c}\text { Degree } \\
\text { Centrality }\end{array}$ & $\begin{array}{c}\text { Node } \\
\text { Betweenness } \\
\text { Centrality }\end{array}$ \\
\hline apparatus & $3,538.00$ & 0.990 & 0.052 & system & $3,352.00$ & 0.990 & 0.052 & method & $7,541.00$ & 0.990 & 0.052 \\
\hline device & $1,185.00$ & 0.867 & 0.033 & server & 904 & 0.847 & 0.032 & service & $1,950.00$ & 0.939 & 0.045 \\
\hline information & 826 & 0.878 & 0.039 & network & 690 & 0.735 & 0.020 & call & 129 & 0.378 & 0.003 \\
\hline computer & 767 & 0.520 & 0.007 & terminal & 588 & 0.724 & 0.019 & processing & 107 & 0.367 & 0.003 \\
\hline medium & 703 & 0.592 & 0.013 & control & 580 & 0.694 & 0.018 & number & 75 & 0.255 & 0.001 \\
\hline user & 614 & 0.724 & 0.022 & communication & 412 & 0.612 & 0.011 & credit & 63 & 0.204 & 0.001 \\
\hline therefore & 521 & 0.531 & 0.008 & payment & 345 & 0.469 & 0.008 & customer & 59 & 0.245 & 0.001 \\
\hline program & 474 & 0.398 & 0.003 & management & 330 & 0.673 & 0.017 & quality & 57 & 0.245 & 0.001 \\
\hline datum & 473 & 0.776 & 0.025 & card & 308 & 0.480 & 0.006 & packet & 55 & 0.224 & 0.001 \\
\hline content & 447 & 0.582 & 0.010 & signal & 308 & 0.367 & 0.003 & identification & 51 & 0.235 & 0.001 \\
\hline advertisement & 313 & 0.439 & 0.004 & access & 192 & 0.418 & 0.003 & offline & 50 & 0.112 & 0.000 \\
\hline video & 311 & 0.367 & 0.003 & transmission & 168 & 0.408 & 0.004 & robot & 49 & 0.204 & 0.001 \\
\hline image & 289 & 0.490 & 0.008 & channel & 156 & 0.327 & 0.002 & & & & \\
\hline readable & 282 & 0.224 & 0.001 & station & 151 & 0.367 & 0.002 & & & & \\
\hline cloud & 263 & 0.418 & 0.003 & point & 150 & 0.357 & 0.003 & & & & \\
\hline application & 239 & 0.571 & 0.010 & resource & 131 & 0.418 & 0.004 & & & & \\
\hline equipment & 210 & 0.459 & 0.005 & radio & 128 & 0.347 & 0.003 & & & & \\
\hline message & 209 & 0.449 & 0.004 & security & 126 & 0.378 & 0.002 & & & & \\
\hline location & 169 & 0.531 & 0.009 & base & 125 & 0.327 & 0.001 & & & & \\
\hline authentication & 150 & 0.398 & 0.004 & power & 95 & 0.347 & 0.003 & & & & \\
\hline shopping & 123 & 0.163 & 0.000 & beacon & 90 & 0.306 & 0.001 & & & & \\
\hline recognition & 112 & 0.327 & 0.002 & area & 89 & 0.173 & 0.000 & & & & \\
\hline
\end{tabular}


Table 1. Cont

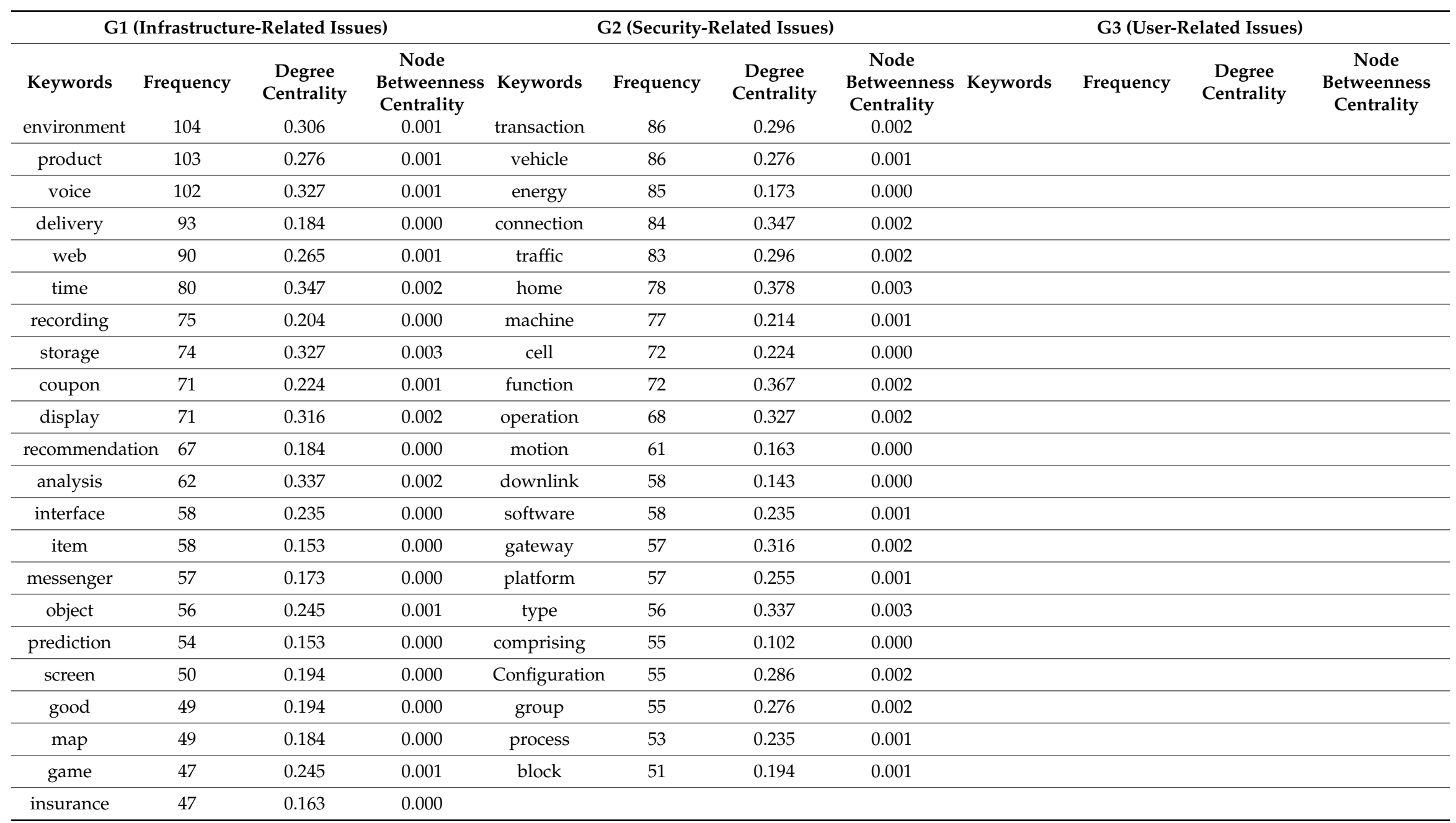

Note: As a result of the analysis, this table was able to obtain frequency, degree centrality, and node betweenness centrality results. The degree centrality represents the value of nodes on the graph, and the node betweenness centrality is a value expressed by quantifying the value between nodes, which is the result of analysis using a network analysis tool. 
Subsequently, this study analyzed the structural characteristics of innovation competencies for each participant in a regulatory sandbox in finance. It was possible to understand the characteristics of each institution through the process of reclassifying the participants participating in the regulatory sandbox system in the fintech by institution.

First, large enterprises actively responded to security-related issues (G2) (35.3\%). Furthermore, infrastructure-related (G1) and user-related (G3) issues showed the same ratio (32.4\%).

Middle-standing enterprises showed the highest ratio of infrastructure-related issues (G1, 37.7\%), which were followed by user-related issues (G3, 33.2\%) and security-related issues (G2, 29.1\%). Furthermore, it was found that middle-standing enterprises were focusing on the development of infrastructure-related and user-related technologies in fintech.

Finally, small and medium-sized enterprises showed the highest ratio of user-related issues (G3, 37.1\%), which were followed by infrastructure-related issues (G1,34.6\%) and security-related issues (G2, 28.3\%). In other words, small companies were developing technologies with a focus on users. (see Table 2 ).

Table 2. Results of group network analysis by industry categorization.

\begin{tabular}{cccccccc}
\hline \multirow{2}{*}{ Division } & \multicolumn{2}{c}{$\begin{array}{c}\text { Large-Sized } \\
\text { Company }\end{array}$} & \multicolumn{2}{c}{$\begin{array}{c}\text { Enterprise of } \\
\text { Middle-Standing }\end{array}$} & $\begin{array}{c}\text { Small and } \\
\text { Medium-Sized } \\
\text { Enterprises }\end{array}$ & $\begin{array}{c}\text { Total by } \\
\text { Group }\end{array}$ \\
\cline { 2 - 7 } & Freq. & $\%$ & Freq. & $\%$ & Freq. & $\%$ & \\
\hline G1 (infrastructure-related issues) & 9290 & $32.4 \%$ & 693 & $37.7 \%$ & 275 & $34.6 \%$ & $104.6 \%$ \\
\hline G2 (security-related issues) & 10121 & $35.3 \%$ & 535 & $29.1 \%$ & 225 & $28.3 \%$ & $92.6 \%$ \\
\hline G3 (user-related issues) & 9297 & $32.4 \%$ & 611 & $33.2 \%$ & 295 & $37.1 \%$ & $102.7 \%$ \\
\hline Total & 28708 & $100 \%$ & 1839 & $100 \%$ & 795 & $100 \%$ & - \\
\hline
\end{tabular}

Regarding the characteristics of each participating enterprise, the results show that large enterprises are focusing on the development of security-related technologies, whereas middle-standing enterprises are focusing on infrastructure-related technologies and small and medium-sized enterprises on user-related innovation competencies. Furthermore, large enterprises are developing security technologies that require relatively high initial costs, which play a key role in infrastructure building for fintech.

Security technology is switching the direction from ex-post exposure to ex-ante prevention for the development of digital technology, which indicates the need to establish a system for risk management and relevant risk prevention. Middle-standing enterprises are improving efficiency and safety in fintech by developing infrastructure-related technologies. Although infrastructure-related technologies are closely related to security-related technologies, they are different in that the former are more focused on detail. An examination of such microscopic mechanisms indicates that it is necessary to establish policies suited to the characteristics of each enterprise type to facilitate institutional development in fintech. (see Figure 3). 


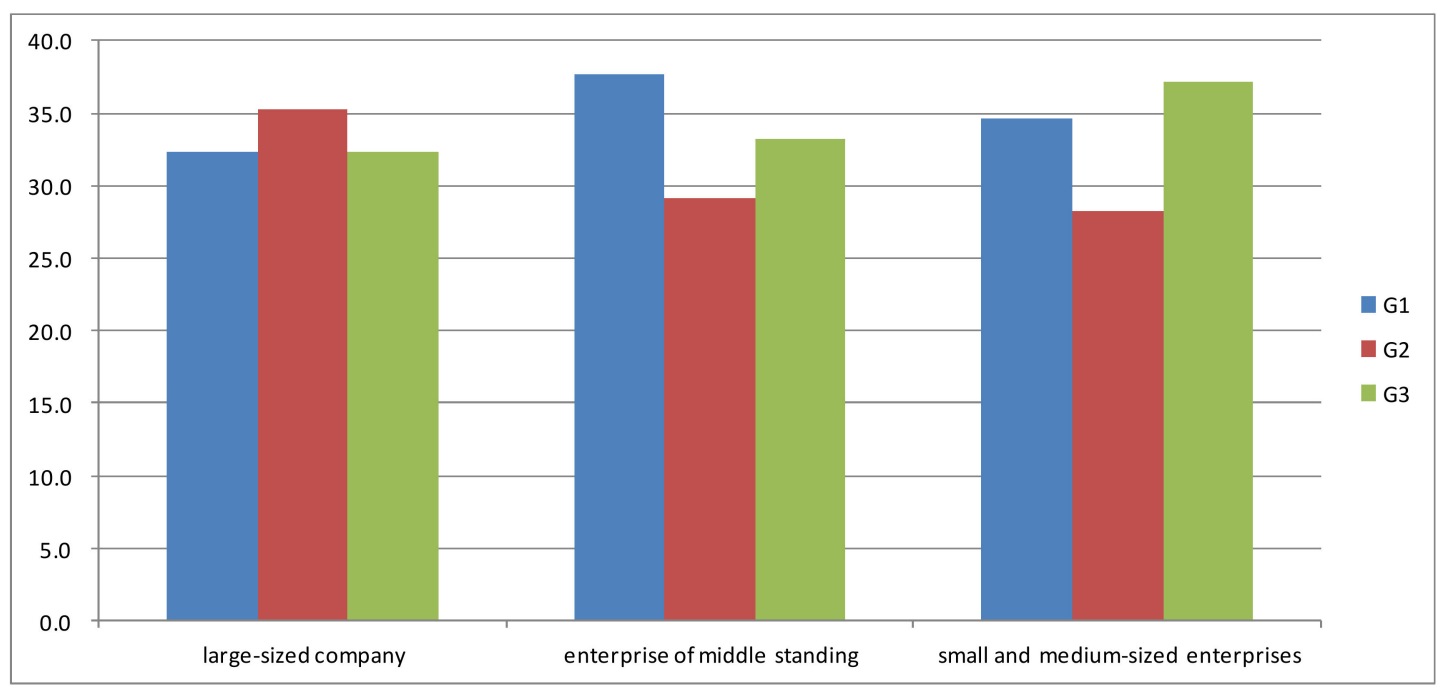

Figure 3. Group network analysis by industry categorization. Note: Data are classified by company and compared with the frequency of words belonging to each group.

\section{Discussion}

The current study analyzed the structural characteristics of the innovation competencies of participating enterprises after the implementation of the regulatory sandbox policy and helped use these characteristics to establish future policies in Korea. Furthermore, this study provides several implications for the development of a regulatory sandbox policy in terms of evidence-based policy.

To date, in the regulatory sandbox policy in Korea, a few policy makers have been effectively supplying policies that consider equity among participants. However, these policy makers have not made sufficient effort to determine the structure and characteristics of the innovation competencies of policy users in terms of the supply process [21-23] because policy makers do not have adequate time and funds to determine innovation competencies. Hence, the efficiency of user-centered policies can be improved by developing a scientific analysis method to analyze the competencies of policy users and including them in policies.

This study determined the MoM as a method to overcome policy failure by completely adopting the best practices implemented in other countries. The study results will help to implement regulatory sandbox policies tailored to the characteristics of South Korean participants to establish a differentiated system and establish strategies to support the participants' MoM.

To examine the MoM of regulatory sandboxes, this study used ACI, which analyzes policies focusing on interactions among actors. The application of ACI determines the institutional settings that affect the policies and examines how actors interact with different preferences and value systems under the constraints of institutional settings [19-24] to better explain the complicated aspects of the process of implementing regulatory sandboxes.

Future research projects can further explain the responses to regulations. For the successful execution of regulatory policies, it is necessary to obtain the compliance of subjects. Additional research using compliance theory must be conducted to explain the responses toward regulations [24-26].

This study has some limitations. It focuses on the innovation competencies of enterprises participating in the sandbox policy, rather than explaining the regulatory sandbox policy itself [27]. Therefore, in-depth discussions and considerations of the regulatory sandbox policy itself are necessary in the future.

\section{Conclusions}

This study focused on the structural characteristics of each type of enterprise participating in the regulatory sandbox policy and attempted to remove difficulties that new industries and services 
experiences during creation due to regulations. To examine the enterprises' MoM, this study collected and analyzed the patent data created by enterprises to analyze their characteristics and help design tailored policies in the future. The results of the analysis are as follows:

By analyzing the enterprise data by group, the innovation competencies of regulatory sandbox participants were classified into infrastructure-, security-, and user-related issues. Infrastructureand security-related issues were closely related, and user-related issues occurred in the development of technologies related to stability in fintech transactions. Furthermore, it was found that fintech technology was developed with a focus on credit guarantee. Previously in Korea, the fintech sector was fostered by the private sector, but the intention is to have the government foster the section. Since the existing regulatory issues can be solved by the government's policy, the government's efforts can have a great impact on the technology development in the fintech field.

The results of the analysis for each type of enterprise reveal that large enterprises are focusing on security, middle-standing enterprises on infrastructure, and small and medium-sized enterprises on user-related issues to develop their innovation competencies. In particular, the security-related issues considered by large enterprises involve relatively high costs in terms of initial technology development and are closely related to the construction of infrastructures. Contrarily, small and medium-sized enterprises are developing technologies and services in fintech with a focus on users. Since the infrastructure sector in the fintech sector in Korea is a sector that requires a high initial cost, it is the role of the government to establish an institutional foundation for well-equipped infrastructure. Therefore, the government's institutional support for each of the infrastructure and technology development sectors should be strengthened in future institutional design of the fintech sector in Korea.

This study can be used to formulate regulatory sandbox policies in the future by determining the MoM of enterprises. In particular, it can be used as a reference to establish policies tailored to the characteristics of each organization type by analyzing the innovation competencies of each enterprise. The regulatory sandbox system in Korea is progressing at a rapid pace with the aim of creating new industries and services in all industries. However, in the process of solving the issues arising in the actual system process behind the creation of results through this sense of speed, a process of transplanting the system suitable for the characteristics of Korea is necessary. Therefore, this research suggests that there is a need for a policy alternative to feedback that can identify the characteristics of companies participating in the regulatory sandbox in the fintech sector and reflect this in the policy.

Author Contributions: Conceptualization, H.C.; methodology, H.C.; validation, H.C.; formal analysis, H.C.; investigation, H.C.; data curation, H.C.; writing-original draft preparation, H.C. and K.L.; writing-review and editing, H.C. and K.L. supervision, H.C. and K.L.; All authors have read and agreed to the published version of the manuscript.

Funding: The publication fee for this manuscript is funded by the Science and Technology Policy Institute (project number: T0200600).

Acknowledgments: This research is supported by STEPI (project number: T0200600, title: Agenda setting research project for technological regulation reform (4th year)). Also, this research is related to "Planning and research to establish basic plan for new industry regulation" (project number: I0202500).

Conflicts of Interest: The authors declare no conflict of interest.

\section{References}

1. Piri, M.M. The changing landscapes of fintech and regtech: Why the United States should create a federal regulatory sandbox. Bus. Fin. L. Rev. 2018, 2, 233.

2. Van der Waal, E.C.; Das, A.M.; van der Schoor, T. Participatory experimentation with energy law: Digging in a 'regulatory sandbox' for local energy initiatives in the Netherlands. Energies 2020, 13, 458. [CrossRef]

3. Hapsari, R.A.; Maroni, M.; Satria, I.; Ariyani, N.D. The existence of regulatory sandbox to encourage the growth of financial technology in Indonesia. Fiat Justisia J. Ilmu Huk. 2019, 13, 271-288. [CrossRef]

4. Edler, J. Demand Oriented Innovation Policy. The Co-Evolution of Innovation Policy Encourage the Growth of Fina Systems and Governance; Working Report No. 99; Office of Technology Assessment at the German Bundestag, TAB: Berlin, Germany, 2006; pp. 1-32. 
5. Allen, H.J. Regulatory sandboxes. Geo. Wash. L. Rev. 2019, 87, 579.

6. Sun, Y. Spatial distribution of patents in China. Reg. Stud. 2000, 34, 441-445. [CrossRef]

7. Acs, Z.J.; Anselin, L.; Varga, A. Patents and innovation counts as measures of regional production of new knowledge. Res. Policy 2002, 31, 1069-1085. [CrossRef]

8. Jenik, I.; Lauer, K. Regulatory Sandboxes and Financial Inclusion; CGAP: Washington, DC, USA, 2017.

9. Zetzsche, D.A.; Buckley, R.P.; Barberis, J.N.; Arner, D.W. Regulating a revolution: From regulatory sandboxes to smart regulation. Fordham J. Corp. Fin. L. 2017, 23, 31. [CrossRef]

10. Grant, A. Proposed Historical Policy Analysis of Project Catalyst's Regulatory Sandbox. Ph.D. Thesis, California State University, Northridge, CA, USA, 2020.

11. Forsman, H. Innovation capacity and innovation development in small enterprises: A comparison between the manufacturing and service sectors. Res. Policy 2011, 40, 739-750. [CrossRef]

12. Lewis, J.M.; Ricard, L.M.; Klijn, E.H. How innovation drivers, networking and leadership shape public sector innovation capacity. Int. Rev. Adm. Sci. 2018, 84, 288-307. [CrossRef]

13. Mehrabani, S.E.; Shajari, M. Knowledge management and innovation capacity. Manag. Res. 2012, 4, 164. [CrossRef]

14. Thomas, L.G. The case for a federal regulatory sandbox for Fintech companies. NC Bank. Inst. 2018, $22,257$.

15. Buckley, R.P.; Arner, D.W.; Veidt, R.; Zetzsche, D.A. Building fintech ecosystems: Regulatory sandboxes, innovation hubs and beyond. UNSW Law Res. Pap. 2019, 19-72. [CrossRef]

16. Einav, L.; Levin, J. The data revolution and economic analysis. Innov. Policy Econ. 2014, 14, 1-24. [CrossRef]

17. Scharpf, F.W. Games Real Actors Play: Actor-Centered Institutionalism in Policy Research; Westview Press: Boulder, CO, USA, 1997; p. 44.

18. Scharpf, F. Institutions in comparative policy research. Comp. Political Stud. 2000, 33, 762-790. [CrossRef]

19. Rudolph, M. User-friendly and tailored policy administration points. In Proceedings of the 1st International Conference on Information Systems Security and Privacy (ICISSP) Doctoral Symposium, Angers, France, 9-11 February 2015.

20. Kim, S.S.; Rideout, C.; Han, H.W.; Lee, L.; Kwon, S.C. Implementing a targeted and culturally tailored policy, systems, and environmental nutrition strategy to reach Korean Americans. Prog. Commun. Health Partnersh. Res. Educ. Action 2018, 12. [CrossRef] [PubMed]

21. Prajogo, D.I.; Ahmed, P.K. Relationships between innovation stimulus, innovation capacity, and innovation performance. RED Manag. 2006, 36, 499-515. [CrossRef]

22. Jørgensen, F.; Ulhøi, J.P. Enhancing innovation capacity in SMEs through early network relationships. Creat. Innov. Manag. 2010, 19, 397-404. [CrossRef]

23. Etienne, J.; Schnyder, G. Improving the micro-foundations of actor-centered institutionalism. SSRN 2010. [CrossRef]

24. Etienne, J. Compliance theory: A goal framing approach. Law Policy 2011, 33, 305-333. [CrossRef]

25. Crick, T.; Mateos-Garcia, J.; Bakhshi, H.; Westlake, S. Innovation Policy-Making in the Big Data Era. In Proceedings of Data for Policy; Cambridge University Press: Cambridge, UK, 2015; pp. 1-4.

26. Kim, N.; Lee, H.; Kim, W.; Lee, H.; Suh, J.H. Dynamic patterns of industry convergence: Evidence from a large amount of unstructured data. Res. Policy 2015, 44, 1734-1748. [CrossRef]

27. Authority Financial Conduct. Regulatory Sandbox. Available online: https://www.fca.org.uk/publication/ research/regulatory-sandbox.pdf (accessed on 1 October 2016).

(C) 2020 by the authors. Licensee MDPI, Basel, Switzerland. This article is an open access article distributed under the terms and conditions of the Creative Commons Attribution (CC BY) license (http://creativecommons.org/licenses/by/4.0/). 